\title{
ISTISHHÂB SEBAGAI TEORI HUKUM ISLAM SEBUAH TINJAUAN HISTORIS
}

\author{
Muhammad Taufiq \\ Fakultas Syariah Institut Agama Islam Negeri (IAIN) Madura | \\ Mh.taufiq.phd@gmail.com \\ DOI: https://doi.org/10.35719/ijl.v1io1.74
}

\begin{abstract}
Although in substance Istishhâb has existed since the era of the Prophet, Istishhâb is still included in the category of Islamic legal propositions that are mukhtalaf fîh (there are differences among scholars). The construction of the new Istishhâb theory began in the fifth hijri adad in a clear and detailed manner. This paper wants to further discuss Istishhâb as a theory of Islamic law, from a historical perspective. From this point of view, it can later be concluded whether Istishhâb can be considered as a theory of Islamic law or just a method of Islamic law istinbath.
\end{abstract}

Keywords: Istishhâb, Theory of Islamic Law, Historically

\begin{abstract}
Abstrak: Meskipun secara substansi Istishhâb sudah ada sejak era Rasulullah, Istishhâb masih masuk kategori dalil hukum Islam yang mukhtalaf fîh (terjadi perbedaan di antar ulama). Kontruksi teori Istishhâb baru dimulai pada adad kelima hijriah secara jelas dan rinci. Tulisan ini ingin membahas lebih jauh Istishhâb sebagai teori Hukum Islam, dari sisi tinjauan historis. Dari sisi tersebut, nantinya bisa disimpulkan apakah Istishhâb bisa dianggap sebagai teori hukum Islam atau sekedar metode istinbath hukum Islam.
\end{abstract}

Kata Kunci: Istishhâb, Teori Hukum Islam, Historis

\section{Pendahuluan}

Islam agama samawi yang sempurna dan terakhir, membawa syariat Allah melalui risalah Nabi Muhammad untuk rahmatan lil alamin. Oleh karena itu, maka Allah menurunkan syariat Islam yang bersifat universal, elastis,

IJLIL: INDONESIAN JOURNAL OF LAW AND ISLAMIC LAW VOLUME 1 NOMOR 1 JULI-DESEMBER 2019;

ISSN 2721-5261

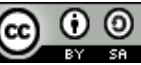


komprehensif, sistematis dan dinamis. Syariat dalam Islam mencakup akidah, fikih dan akhlak. Hal ini dibuktikan dengan adanya prinsip syariat Islam yang berdasarkan prinsip tauhid, al-tadrîj fi al-tasyrî', 'adamu al-harâj, qillatu al-Takâlif, maslahah 'ammah'.

Secara kongkret hal ini ditunjukkan oleh dua permasalahan yang sangat prinsip yaitu an-nushus mahdudah wal waqaiq ghair mahdudah; teks-teks suci al-Quran dan hadits yang menjadi sumber hukum Islam terbatas dan tak mengalami perubahan sedangkan dinamika permasalahan yang terjadi sangat dinamis dan selalu berubah dari era ke era. Kedua hal inilah yang kemudian memunculkan terbukanya pintu ijtihad bagi para mujtahid yang telah dijelaskan secara terperinci oleh teks suci al-Qurân dan hadits.

Di era Rasulullah, pintu ijtihad bagi para sahabat masih belum berlaku, karena semua hasil ijtihad para sahabat harus mendapatkan legitimasi (al-Taqrîr) ${ }^{2}$ dari Rasulullah ${ }^{3}$. Ketika Rasulullah wafat, permasalahan sudah mulai banyak

\footnotetext{
${ }^{1}$ Lima prinsip dasar ini mencakup moderasi (al-wasathiyah), keadilan (al-‘adalah), Amar makruf nahi munkar, kemerdekaan (al-Hurriyah), persamaan (al-musawah), tolong menolong (al-Ta'awun), toleransi (al-Tasamuh), kemanusiaan (al-Insaniyah) dan konsisten (al-Istiqamah).

${ }^{2}$ Taqrir termasuk hadits Rasulullah yang berupa pengakuan Rasulullah terhadap suatu permasalahan. Hadits terbagi dalam tiga bagian. Pertama, perkataan Rasulullah yang disebut Qaul. Kedua, pekerjaan Rasulullah saw (baca, $f i^{\prime}$ ). Ketiga, keputusan Rasulullah saw yang dikenal dengan al-taqrir. Lihat! Al-Syirazy, Al-Ma'ũnah fi al-Jadãl, (Kuwait: Jam'iyah al-Turaś al-Islamĩ, 1407 H), juz 1, hal. 29.

3 Pada masa ini disebut masa awal pembentukan syariat Islam dan sedikit terjadi perbedaan pendapat. Karena jika ada perbedaan pendapat, bisa diputuskan oleh Rasulullah. Lihat! Mushtada Sa'ide Al-Khin, Dirãsah tãrikhiyah lil fikhi wa ușũlihi, (Demasyqus: al-Syirkah al-Muttahidah li al-Tawzi', 1415 H/ 1995 M), hal. 15-47.
} 
bermunculan, dimulai dari proses suksesi khalifah pengganti setelah Rasulullah wafat. Permasalahan tersebut diselesaikan dengan ijtihad para sahabat dengan sistem syura (demokrasi) bahwa suara terbanyak menunjuk Sayyidina Abu Bakar sebagai Khalifah pertama4.

Munculnya terma ijtihad dalam arti teknis, dalam tinjauan historis, biasanya merujuk pada kasus Sahabat Mu'az ibn Jabal yang diutus oleh Rasul untuk mengemban tugas kehakiman di Negeri Yaman. ${ }^{5}$

Riwayat ini, sering kali dijadikan sebagai justifikasi terhadap cikal bakal munculnya ijtihad pada masa Rasul. "Rekomendasi" Rasulullah dalam hal ini, pada periode berikutnya, ternyata memberikan pengaruh yang besar terhadap tradisi penggunaan penalaran logika ( $r a y u$ ) dalam menangkap makna teks.

Sehingga pada gilirannya, bermunculan nama-nama Sahabat Rasulullah seperti, Abu Bakar As-Shiddiq, 'Umar bin Khattab, Utsman bin Affan, Ali bin Abi Thalib, Ibnu 'Abbas, Ibnu Mas'ud, Zaid ibn Sabit, dan Muazd Ben Jabal ${ }^{6}$ sendiri, yang menggunakan penalaran logika ketika menghadapi persoalan-persoalan yang belum mendapatkan kepastian hukum dalam teks suci al-Quran dan Sunnah.

\footnotetext{
${ }^{4}$ Musthafa Bashir al-Tharabalisy, Manhãju al-Bahśi wa al-Fatwã, (Yordania: Dar al-Fath, $2010 \mathrm{M} / 1431 \mathrm{H})$, hal. 19.

${ }^{5}$ Lihat Ahmad bin Hambal, Musnad al-Imam Ahmad ibn Hanbal, (Beirut: Dar al-Kotob alIslamiyah, 1993), juz IV, hal. 252.

${ }^{6}$ Muhammed Ali Al-Sais, Nasy'ah al- Fiqh al-Ijtihadi wa Athawârih, (Kairo: Majma' alBuhuts al-Islamiyah, 1970), hal. 36-75.
} 
Menurut Ali as-Sais, ${ }^{7}$ ijtihad $\quad(r a y u)$ sahabat mmengandung arti yang sangat luas (bi ma'nahu al-wâsi'), yakni tidak hanya terbatas pada bentuk yang pada masa berikutnya dipahami sebagai qiyâs, istihsân, dan mashlahah, namun juga mencakup saddu azzarâi', 'urf dan Istishhâb. Kata ra'yu dalam konteks ini, dipahami sebagai suatu produk penalaran (al-qalb) pasca pemikiran yang dalam, mencermati (ta'ammul) serta melakukan pencarian (thalab) terhadap kebenaran dari berbagai dalil teks suci yang tampak seperti bertentangan.

Dalam tulisan ini, penulis akan menelusuri akar sejarah Istishhâb, sebagai salah satu produk ra'yu, diawali dari masa Rasul, sahabat sampai pada masa Syaukani, yang dimulai dengan penjelasan tentang definisi Istishhâb itu sendiri.

\section{Pembahasan}

\section{Istishhâb}

Menurut Bahasa Istishhâb adalah mernyertakan dan membawa serta dan tidak melepaskan sesuatu. ${ }^{8}$

Jika ada seorang berkata: استصحبت الكتاب في سفري berarti: aku membawa buku bersamaku di perjalanku. Istishhâb adalah kata kerja enam huruf (fi'lu tsulâsi mazîd bi tsalâsati ahruf) dari kata istashaba, yastashibu, Istishhâban

\footnotetext{
${ }^{7}$ Ibid, hal. 37.

${ }^{8}$ Lihat Lisan al-Arab, term sha-hi-ba
} 
dengan wazan istafala, yastafilu, istifâlan. Bentuk tsulâtsi mujarradnya adalah shahaba, yashabu, suhbatan yang berarti menemani, berkawan dengan, menjadikan kawan. ${ }^{9}$ Istashaba sendiri dimaknakan dengan bersikap ramah pada, lemah lembut terhadap. ${ }^{10}$

Ungkapan istashaba ar-rajul berarti mengajak seseorang kepada persahabatan. Dari sini, selanjutnya dapat dikatakan bahwa apa saja yang menemani sesuatu disebut Istishhâb. Hal ini kemudian diperjelas oleh al-Isfahani bahwa setiap yang menemani sesuatu, baik ia manusia, hewan, tempat maupun waktu dinamakan Istishhâb. ${ }^{11}$

Dalam hal ini tidak ada perbedaan antara menemani dengan badan (fisik), dengan pertolongan atau menemani dengan tujuan. ${ }^{12}$ Kata $s-h-b$ dan segala bentuk derivasinya disebutkan sebanyak sembilan kali dalam sembilan puluh delapan ayat. ${ }^{13}$ Kata yushabun ${ }^{14}$ diterjemahkan oleh atThabari (w. $310 \mathrm{H}$ ) dengan yunsarun, yuhfazun dan yujarun. ${ }^{15}$ Sedangkan dalam hadis-hadis Rasulullah, kata $s$ $h-b$ dan berbagai bentuk derivasinya juga sangat banyak

\footnotetext{
${ }^{9}$ Ahmad Warson Munawwir, Kamud al-Munawwir, (Yogyakarta: Pondok Pesantren AlMunawwir Krapyak, 19844), hal. 816.

${ }^{10}$ Ibid, hal. 817.

${ }^{11}$ Ibn Manzur, Lisânu al-Arab, (Mesir: Dar al-Misriyah, tt.), Juz II, hal. 8.

${ }^{12}$ Ar-Ragheb al-Isfahany, Mu'jam Mufradat al-Alfadh al-Quran, (Beirut: Dar el-Fikr, tt.), hal. 282.

${ }^{13}$ Muhammed Fuad Abd El-Baqi, al-Mu'jam al- Mufahras li alfadh al-Quran al-Karim, (Indonesia: Maktabah Dahlan, tt.), hal. 509-511.

${ }^{14}$ QS. al-Anbiya : 43

${ }^{15}$ Muhammad Ibnu Jari al-Thabary, Jam'u al-Bayan ‘an Ta'wil al-Quran, (Mesir: Mushtafa al-Babi al-Halabi wa Awladuh, 1968), Jux XV, hal. 30-31.
} 
ditemukan. Diantaranya dalam teks hadits, "allahumma ishabnâ fi safarina..." Ishâb dalam hadis ini bermakna menjaga, memelihara atau melindungi.

Adapun dalam istilah Ushul Fikih, banyak para ulama Ushul Fikih mendefinisikan Istishhâb ke dalam berbagai definisi.

Al-Imam Muhammad al-Ghazali memberikan definisi Istishhâb dengan berpedoman pada dalil baik akal maupun syariat, bukan karena faktor ketidaktahuan dengan adanya dalil, melainkan setelah dilakukan riset, peneltian dan pembahasan dengan sangat teliti, didapatkan tidak adanya dalil yang mengubahnya. ${ }^{17}$

Menurut Al-Imam Al-Isnawy menyatakan bahwa "Istishhâb adalah kepastian hukum terhadap suatu masalah di masa setelahnya atas dasar kepastian hukum yang sudah berlaku pada masa sebelumnya, karena tidak adanya dalil yang mengubah kepastian hukum tersebut. ${ }^{18}$

Sedangkan, menurut Imam Muhammed Ubaidillah AlAs'ady, Istishhâb adalah penetapan hukum atas suatu permasalahan berdasarkan dalil penetapan hukum yang

\footnotetext{
${ }^{16}$ Ahmad Ibn Hanbal, op. cit., vol. V, hal. 83

${ }^{17}$ Abu Hamid al-Ghazali, al-Mustashfâ Fi Ilmi al-Ushûl, (Beirut: Dar al-Kutub alllmiyah, 1993), hal. 159.

${ }^{18}$ Abdurrahim al-Isnawy, Nihâyah al-Sûl syarh minhâju al-wushûl, (Beirut: Dar al-Kutub al-Ilmiyah, 1999) jilid. 3, hal. 131.
} 
sudah ada dan dipastikan tetap berlaku sampai ada dalil lain yang menggantinya. ${ }^{19}$

Adapun Al-Imam Al-Qarafy (w. 486 H) -dari kalangan ulama Malikiyah- mendefinisikan Istishhâb sebagai keyakinan bahwa kepastian hukum di masa lalu dan sekarang berkonsekuensi pada eksistensi dalil di masa sekarang atau akan datang. ${ }^{20}$ Definisi Imam Al-Qarafy ini memberikan petunjuk bahwa Istishhâb sesungguhnya merupakan penetapan hukum suatu masalah di masa kini ataupun yang akan datang berdasarkan apa yang telah berlaku pada masa sebelumnya.

Misalnya, penetapan bahwa Ali memiliki sebuah rumah dan toko melalui akad jual beli, maka selama tidak dalil lain, bukti atau akad lain yang mengubah kepemilikan Ali, maka kepastian hukumnya bahwa Ali adalah pemilik rumah dan toko tersebut sampai kapan pun. Atau misalnya, Status wilayah Republik Indonesia adalah Darul Islam $^{21}$ yang berasaskan Pancasila, maka selama tidak ada dalil lain yang mengubahnya maka status wilayah Republik Indonesia adalah Darul Islam yang berasaskan Pancasila sampai kapan pun. Dengan kata lain, Istishhâb merupakan legitimasi

\footnotetext{
${ }^{19}$ Muhammad Ubaidillah al-As'adi, al-Mûjiz Fi Ushûl al-Fiqh, (Dar asSalam, 1990), hal. 251

${ }^{20}$ Abu al-Abbas Ahmad ibn Idris al-Qarafy, Syarh Tanqih al-Fushul, (Al-Faniyah alMuttahidah, cet. 1, 1973), hal. 199.

${ }^{21}$ Hasil Keputusan Muktamar NU di Banjarmasin tahun 1936 yang merujuk kepada Fatawa al-Masyhur. Lihat! Abdur Rahman bin Muhammad bin Husei al-Masyhur, Bughyatu al-Mustarsyidin (Tarem; Markaz al-Nur li al-Dirasat wa al-Abhats, 2009 M/1430 H), juz. 4, hal. 330 .
} 
pemberlakuan kepastian kepastian hukum dari masa sebelumnya, sekarang dan akan datang. ${ }^{22}$

\section{Istishhâb di Era Rasulullah, Sahabat dan Tabiin}

Sebenarnya Istishhâb pada masa-masa awal Islam, sudah mempunyai embrio, memiliki hakikat, namun belum mempunyai nama. Dalam konteks inilah Istishhâb dibicarakan. Contoh Istishhâb yang disebutkan oleh alQuran seperti dalam kasus ditolaknya kesaksian seseorang yang menuduh perempuan baik-baik (muhsanat) melakukan perzinaan, tetapi tidak bisa menunjukkan empat orang saksi,

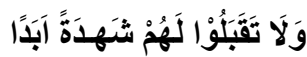

Artinya: “janganlah kamu terima kesaksian mereka untuk selama-lamanya"23.

Dalam ayat ini ditegaskan bahwa kesaksian qâzif (si penuduh) tidak dapat diterima. Masa berlakunya penolakan kesaksian mereka. menurut Abdul Wahab alKhallaf, ${ }^{24}$ tidak hanya terbatas pada saat itu, melainkan berlaku sepanjang masa. Hal ini dipahami dari kata abâdan yang berarti selama-selamanya. Tentu saja selama tidak ada hal lain yang membatalkannya yakni melakukan taubat dan memperbaiki diri.

\footnotetext{
${ }^{22}$ Sya'ban Muhammad Ismail, Ushûl al-Fiqh al-Muyassar, (Beirut: Dar Ibn Hazm, 2006), juz 2, hal. 103-104.

${ }^{23}$ Q.S. al-Nur (24): 4 .

${ }^{24}$ Abdul Wahab Khallaf, Mashâdir at-Tasyrî’ al-Islâmi Fîmâ Lâ Nashsha Fîhi, (Beirut: Dar al-Qalam, tt.), hal. 151.
} 
Muhammad Taufiq

Ayat di atas juga secara tersirat menjelaskan bahwa seorang muslim pada dasarnya 'iffah, terjaga dari melakukan perbuatan zina, karena akal dan agama yang dimilikinya, menahan dirinya dari melakukan perbuatan buruk tersebut. $^{25}$

Jadi, jika orang yang menuduh tidak dapat mendatangkan saksi-saksi untuk memperkuat tuduhannya, maka selama itu pula seorang muslim/muslimah tetap pada kondisinya semula yakni terhindar dari melakukan hal-hal yang dilarang. Pada contoh lain misalnya, seseorang yang telah berwudu', menurut Rasul, juga tetap dalam keadaan semula, yakni suci dari hadas, selama ia tidak mendengar "suara" atau mencium "bau" (karena angin yang keluar dari lubang pelepasan). ${ }^{26}$

Dari penjelasan teks suci ayat Al-Qurân dan Hadis, terdapat indikasi bahwa Istishhâb dalam arti hakikat tanpa nama, sudah ada sejak masa Rasulullah, demikian pula pada masa berikutnya yakni masa sahabat dan tabi'in. Seperti telah dijelaskan sebelumnya bahwa ijtihad sahabat mengandung arti luas yakni tidak hanya terbatas pada qiyas, istihsan dan maslahah, namun juga mencakup sad az-zara’i, 'urf dan Istishhâb. Hanya saja, dalam hal ini, Syekh

\footnotetext{
${ }^{25}$ Hafizuddin an-Nusaifi, Kasyfu al-Asrar, (Beirut: Dar al-Kutub al-Ilmiyah, 1986), juz II, hal. 452

${ }^{26}$ Hal ini berdasarkan hadis Rasulullah. Lihat! An-Nawawi, Syarh Muslim, (Beirut: Dar al-Kutûb al-Ilmiyah, 1986, IV: 45
} 
Muhammad Moesa Towana tidak menggunakan istilah Istishhâb, melainkan konsep al-bara'ah al-ashliyah. ${ }^{27}$

Syekh Muhammad Moesa menjabarkan bahwa dalam sebuah permasalahan seorang wanita dalam masa iddah, menikah dengan pria lain, Sayyidina Umar bin Khattab menegaskan bahwa pria tersebut tidak boleh melakukan hubungan pasangan suami istri selamanya atau disebut dengan istilah hurmah muabbadah. Hal ini berdasarkan agar tidak terjadi penyimpangan terhadap syariat Allah yang memiliki tujuan untuk menjaga keturunan (hifdzu an-nasl).

Berbeda dengan Sayyidina Ali ibn Abi Thalib yang memberikan kepastian hukum atau fatwa yang berbeda dengan fatwa Umar bin Khattab. Menurut Sayyidina Ali, pria tersebut diperbolehkan melakukan hubungan intim jika masa iddahnya berakhir. Dalam perbedaan pendapat ini, SayyidUmar ibn Khattab berpegang pada dalil al-mashlahah al-mursalah. ${ }^{28}$ Sedangkan Sayyidina Ali bin Abi Thalib menggunakan metode al-bara'ah al-ashliyah (Istishhâb). ${ }^{29}$

Fatwa Sayyidina Ali ini berdasarkan keuniversalan ayat “maka nikahilah wanita-wanita yang kamu senangi dua, tiga atau empat” ${ }^{\circ}$. Dan “... dan dihalalkan bagi kamu selain hal

\footnotetext{
${ }^{27}$ Muhammad Musa Towana, al-Ijtihâd, (Mesir, Dar al-Kutûb al-Hadîtsah, 1971), hal. 40 .

${ }^{28}$ Untuk lebih jelasnya tentang pembahasa ijtihad Umar yang bersandar pada pertimbangan Maslahah. Lihat! Abu Zahrah, Târikh al-Madzâhib al-Islâmiyah,(Beirut: Dar al-Fikr, tt.), juz II, hal. 20-21.

${ }^{29}$ Towana, al-Ijtihâd,..., ibid.

${ }^{30}$ Q.S. An-Nisa' (4): 3
} 
yang demikian itu (yaitu) mencari istri-istri dengan hartamu untuk dinikahi secara sah bukan untuk berzina". ${ }^{31}$

Pasca era sahabat, mayoritas Tabi'in berpendapat bahwa segala sesuatu pada dasarnya adalah boleh (al-ibahah), kecuali ada dalil teks suci yang melarangnya. Hal tersebut bertujuan untuk menjaga prinsip syariat Islam yang selalu memberikan kemudahan (qillatu al-Takalif) dan menghindarkan dari kesulitan ('adamu al-haraj). Hal ini dikemukana mayoritas Tabi'in di antaranya oleh Said ibn al-Musayyib, Salim ben Umar, Shuraih al-Qodhy, Atho' ben Rabah, Zuhri dan Umar ben Abd Al-Aziz. Mereka menegaskan bahwa mendegarkan nyanyian dan alat musik rebana tidaklah haram selama tidak menimbulkan mafsadat dan mengajak pada hal negatif (mungkar) serta tidak memalingkan hati dan timbul rangsangan negatif. Mendengarkan nyanyian dan alat musik dihalalkan selama tidak ada teks yang mengharamkan. Menurut Salam Madkur, pendapat mayoritas Tabi'in ini sebenarnya dianut oleh mayoritas para Sahabat pada masa

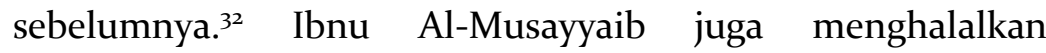
membaca teks suci al-Qurân bagi seorang yang dalam keadaan junub dengan syarat tidak menyentuhnya mushafnya. ${ }^{33}$

\footnotetext{
${ }^{31}$ Q.S. An-Nisa' (4): 24.

${ }^{32}$ Muhammad salam Madkur, al-Ijtihâd Fi Tasyrî̀ al-Islâmi, (Kairo: Dar anNahdah al-Arabiyah, 1992), jilid I, hal. 69.

33 Ibid.
} 
Istishhâb: Dari Imam As-Syafi'i Hingga Imam AsSyaukany Al-Yamany

Sampai pada era Imam Malik (w.179 H), Istishhâb belum terkonstruksi secara jelas. Sekalipun demikian, menurut Muhammad Musa Towana, ${ }^{34}$ salah satu tariqah al-ijtihad yang dilakukan Malik adalah menggunakan Istishhâb. Contoh kasus dalam hal ini adalah masalah talak. Apabila seorang suami ragu, apakah ia telah menceraikan isterinya atau belum, maka diambil hukum asal yakni tetap dalam pernikahan. Maknanya, talak tidak terjadi. Namun, jika ia yakin telah menceraikan isterinya tetapi ragu apakah telah menjatuhkan talak satu, dua atau tiga, maka dihukumkan bahwa ia telah menjatuhkan talak tiga. ${ }^{35}$

Hal ini karena talak terjadi dengan keyakinan. Di sisi lain diperoleh keraguan (syak) tentang tetapnya ruju', sedangkan ruju' tidak dapat ditetapkan dengan keraguan. Apabila dipertanyakan lebih jauh, bagaimana konsep baku Istishhâb yang dimaksud oleh Malik (?) Pertanyaan seperti ini tampaknya memang sulit terjawab. Dari beberapa literatur yang ada, tidak ditemukan secara jelas jawaban mengenai hal ini.

Dalam menjawab berbagai persoalan serta menghindari segala sesuatu yang dapat merusak hukum

\footnotetext{
34 Towana, al-Ijtihâd,..., hal. 72 .

${ }^{35}$ Ibn Hazm al-Andalusi, al-Ahkâm Fi Ushûl al-Ahkâm, (Kairo: Dar al-Hadis, 1992), juz V, hal. 7 .
} 
Allah, Imam Syafi'i tidak menggunakan konsep istihsan dan istislah, melainkan Istishhâb. Dengan konsep ini ia mencoba mencari suatu hubungan dan prinsip pembuktian dengan jalan mengukuhkan peristiwa-peistiwa yang dianggap telah memiliki asal-usul atau sumber yang sah menurut hukum disertai dengan pengakuan eksistensinya, hingga terlihat hal-hal yang berlawanan. Salah satu contoh mengenai hal ini, adalah pendapat Imam Syafi' ${ }^{36}{ }^{6}$ mengenai kebolehan dalam penjualan 'arâya (menjual buah kurma yang masih berada di pohon dengan pembayaran kurma kering seperti barter). Syafi'i menggunakan Istishhâb dalam menyelesaikan masalah ini, yakni tetap memberlakukan hadis Rasulullah yang diriwayatkan dari Zaid ibn Sabit mengenai kebolehan jenis barter ini sebagai sebuah pengecualian. Penggunaan Istishhâb oleh Imam Syafi'i dalam kasus ini, menurut Ahmad hasan, ${ }^{37}$ bukanlah dalam pengertian yang baku melainkan dalam pengertian non teknis.

Bahkan dalam kasus-kasus lain, Imam al-Ghazali menyatakan bahwa Imam Syafi'i berpegang pada Istishhâb dan dalil akal, tidak dengan dalil ijma'. Hanya saja, apabila ditelusuri lebih jauh, tidak ditemukan kata Istishhâb dalam kitabnya ar-Risalah. Istishhâb dalam arti yang jelas, baru

\footnotetext{
${ }^{36}$ As-Syafi'i, al-Umm, (Kairo: tp, 1325), jilid VII, hal. 182.

${ }^{37}$ Ahmad Hasan, Pintu Ijtihad Sebelum Tertutup, (Bandung: Pustaka, 1984), hal. 199.
} 
dijumpai dalam tulisan Muhammad ibn Ali al-Bashri $(\mathrm{w} .436 \mathrm{H}) .^{38}$

Menurutnya, Istishhâb al-hal adalah hukum yang tetap pada suatu kondisi dari berbagai kondisi yang ada, sampai berubahnya kondisi tersebut. Contoh Istishhâb yang digunakan adalah mengenai kewajiban berwudhu' bagi orang yang melakukan tayammum, apabila ia menemukan air. Dalam kitab al-Luma', contoh yang sama dengan di atas, juga dinyatakan oleh Imam al-Fairuz Abadi (w.476 H). Bahkan ia menisbahkan hal ini sebagai perkataan Imam Syafi'i. Lebih lanjut Fairuz membagi Istishhâb al-hal menjadi dua bagian yakni Istishhâb al-hal al-'aql dan Istishhâb al-hal al-ijma'. Ia menambahkan bahwa Istishhâb dapat dipakai sebagai dalil baik dalam menetapkan hukum (al-isbat) maupun meniadakan hukum (an-nafy). ${ }^{39}$

Sampel yang kerap dipergunakan adalah perihal orang hilang (al-mafqûd). Orang yang hilang dan tidak diketahui apakah ia masih hidup atau sebaliknya, maka berdasarkan Istishhâb, ia dihukum masih hidup, selama tidak ada fakta yang menunjukkan kematiannya. Oleh karena itu, jika ada ahli warisnya yang meninggal dunia, maka ia berhak memperoleh warisan.

\footnotetext{
${ }^{38}$ Muhammad ibn Ali al-Bashri, al-Mu’tamâd Fi Ushûl al-Fiqh,(Damsyiq: Dar al-Fikr, 1965), jilid II, hal. 884 .

39 Ibrahim ibn Ali al-Fairuz Abadi, al-Lumâ' Fi Ushûl al-Fiqh, (Beirut: Dar alKutub alIlmiyah, 1985), hal. 122.
} 
Demikian pula halnya dengan wasiat. Di sisi lain, hartanya masih tetap berada dalam tanggung jawabnya, tidak boleh diwariskan. Bila ia mempunyai istri, maka istri tersebut tidak boleh dinikahi oleh siapa pun..$^{40}$

Menurut Imam As-Sarakhsi (w.49o H), dalam kasus almafqûd ini, orang yang hilang tidak dapat menerima warisan, karena mereka tidak dapat dipastikan hidup. Alasan mereka, Istishhâb menjadi hujjah bukan dalam bentuk penetapan melainkan penolakan (li ad-dafi).

Adapun mengenai pembagian Istishhâb secara lebih rinci, Fairuz Abadi dapat dikatakan sebagai orang pertama yang berbicara mengenai hal ini, seperti yang telah dijelaskan sebelumnya. Tentang pembagian Istishhâb ini, Sarakhsi membaginya menjadi empat macam. Pertama, Istishhâb hukm al-hal disertai adanya keyakinan tentang tidak adanya dalil lain yang mengubahnya. Kedua, Istishhâb hukm al-hal setelah adanya dalil yang mengubahnya yang bersifat tetap, dengan jalan penyelidikan dan ijtihad dengan segenap kemampuan. Ketiga, Istishhâb hukm alhal sebelum adanya penyelidikan dan ijtihad dalam mencari dalil yang mengubahnya. Keempat, Istishhâb hukm al-hal untuk menetapkan hukum awal (ibtidâ').41

\footnotetext{
$4^{\circ}$ Al-Bannani, Hasyiyah al-Bannanî 'alâ Matan Jam’i al-Jawâmi',(Semarang, Toha Putra, tt.) jilid II, hal. 349; Muhammad Abu Zahrah, Ushul al-Fiqh,(Mesir: Dar al-Fikr al-Arabi, 1958, hal. 297; dan Ahmad ibn al-Lathifal-Hathib, an-Nafahât 'ala Syarh alWaraqât,(Surabaya: Bungkul Indah, tt.), hal. 150.

${ }^{41}$ Ibid.
} 
Istishhâb dalam bentuk ketiga dan keempat ini, menurutnya, tidak dapat dijadikan hujjah. Sementara itu, Imam Al-Ghazali mengklasifikasikan Istishhâb dalam empat klasifikasi. Pertama, Istishhâb bara'a dzimmah, kedua, Istishhâb al-'umum wan nash. Ketiga, Istishhâb hukm dalla as-syar'u 'ala tsubûtihi wa dawamihi. Keempat, Istishhâb alijmâ' fi mahal al-khilaf. Istishhâb yang terakhir ini terdapat perbedaan pendapat ulama mengenai kehujjahannya. ${ }^{42}$

Al-Imam al-Shaukany (w. $1255 \mathrm{H}$ ) tidak terlalu berbeda dengan al-Imam Al-Sarakhsy dan Al-Imam Al-Ghazaly. Belai juga mengklasifikan Istishhâb menjadi empat yakni Istishhâb ma dalla al-'aqlu wa al-syar'u 'ala tsubûtihi wa dawâmihi, Istishhâbu al-ashli, Istishhâbu al-hukmi al-'aqli, Istishhâbu aldalil ma'a ihtimal al-mu'arid.

Walhasil, Istishhâb yang telah terbangun dengan jelas dan terperinci ini kemudian melahirkan kaidah fikih yaitu di antaranya al-yaqin la yuzalu bi al-syak, al-ashlu fi al-dzimmah al-bara'ah, al-ashlu fi al-ashya' al-Ibahah dan al-ashlu baqa'u ma kana 'ala ma kana. ${ }^{43}$

\section{Istishhâb menurut Madzhab}

\footnotetext{
$4^{2}$ Abu Hamid al-Ghazali, al-Mustashfâ Fi Ilm al-Ushul, (Beirut: Dar al-Kutub alIlmiyah, 1993), hal. 159-160

43 Jalaluddin al-Rahmat al-Suyuthy, al-ashbah wa an-nadzair, (Singapura: Sulaiman Mar'i, tt.), hal. 56, 59 dan 66.
} 
Muhammad Taufiq

Ulama madzhab terjadi silang pendapat dalam legalitas Istishhâb sebagai hujjah. Dalam hal ini, terbagi menjadi tiga pendapat sebagai berikut:44

Pertama, pendapat mayoritas Ulama; Madzhab Maliki, Syafii, Hambali menegaskan bahwa Istishhâb adalah hujjah secara mutlak.

Kedua, pendapat Muta'akhir madzhab Hanafi, menyatakan bahwa Istishhâb adalah hujjah dalam peniadaan hukum asal.

Ketiga, pendapat mayoritas madzhab Hanafi, abu alHasan al-Bashry, mengatakan bahwa Istishhâb tidak memiliki lebagalitas hujjah dalam tatanan metodologi istimbath hukum Islam.

\section{Kesimpulan}

Secara historis, Istishhâb sudah mempunyai embrio sejak masa Rasul. Hal ini terlihat dari nash-nashyang telah disebutkan. Sahabat dan tabi'in juga telah menggunakan Istishhâb dalam arti hakikat, pada saat mereka dihadapkan dengan beberapa persoalan. Namun konstruksi Istishhâb itu sendiri baru dibangun pada abad kelima hijrah disertai dengan pembagiannya secara jelas dan rinci. Dari Istishhâb ini, para ulama fikih belakangan kemudian

44 Mushtafa Deb Al-Bugha, Atsâru al-Adillah al-Mukhtalaf fiha fi al-Fiqh al-Islami, (Demasyq: Dar al-Qalam, cet. 4, 2007), hal. 188-189. 
menetapkan beberapa kaedah umum yang dianggap sebagai patron rujukan berbagai kaus yang terjadi kemudian.

Dari penjelasan di atas, dapat diambil kesimpulan bahwa Istishhâb bukanlah metode penetapan hukum (thuruqu al-Istinbâth). Tetapi substansinya lebih kepada menguatkan suatu dalil agar tetap berlaku sampai ada dalil lain yang mengubahnya. Hal ini sangat urgen agar legalitas dalil tetap berlaku dalam kepastian penetapan hukum Islam. Alhasil setiap suatu hukum asalnya boleh (mubah) sampai ada dalil yang menyatakan haram. Namun apabila hukum asalnya adalah haram seperti hubungan pria wanita, maka hukumya tetap haram kecuali ada dalil yang menghalalkannya, misalnya dengan akad pernikahan.

\section{Daftar Pustaka}

Al-Qurân dan Terjemahannya, Departemen Agama Republik Indonesia, (Surabaya: Surya Cipta Aksara, 1993).

Abdul Wahab Khallaf, Mashadir at-Tasyri' al-Islami Fima La Nassa Fih,(Beirut: Dar al-Qalam, tt.)

Abdurrahim al-Isnawy, Nihayah al-Sul syarh minhaju alwushul, (Beirut: Dar al-Kutub al-Ilmiyah, 1999).

Abu Bakar as-Sarakhsi, Ushul al-Sarakhsi, (Hyderabad: alMaarif an-Na'mamiyah, tt.). 
Abu al-Abbas Ahmad ibn Idris al-Qarafy, Syarh Tanqih alFushul, (Al-Faniyah al-Muttahidah, cet. 1, 1973).

Abu Hamid al-Ghazali, al-Mustashfa Fi Ilm al-Ushul, (Beirut:

Dar al-Kutub al-Ilmiyah, 1993).

Abu Zahrah, Tarikh al-Mazahib al-Islamiyah,(Beirut: Dar alFikr, tt.).

Ahmad ibn al-Lathif al-Hathib, an-Nafahat 'ala Syarh alWaraqat, (Surabaya: Bungkul Indah, tt.).

Ahmad Hasan, Pintu Ijtihad Sebelum Tertutup,(Bandung: Pustaka, 1984).

Ahmad ibn Hanbal, Musnad al-Imam Ahmad Ibn Hanbal,(Beirut: Dar al-Kutub al-Islamiyah, 1993).

Al-Bannani, Hasyiyah al-Bannani 'ala Matan Jam’i alJawami', (Semarang, Toha Putra, tt.)

An-Nawawi, Syarh Muslim, (Beirut: Dar al_kutub alIlmiyah, 1986).

As-Syafi'i, al-Umm, (Kairo: tp, 1325).

Dr. Mushtafa Dib al-Bugha, Atsra al-Adillah al-Mukhtalaf fiha fi al-Fiqh al-Islamy, (Demasyq: Dar al-Qalam, cet. 4, 2007)

Hafizuddin an-Nusaifi, Kasyf al-Asrar, (Beirut: Dar alKutub alIlmiyah, 1986).

Ibn Hazm al-Andalusi, al-Ahkam Fi Ushul al-Ahkam,(Kairo: Dar al-Hadis, 1992). Ibrahim ibn Ali al-Fairuz Abadi, al-Luma' Fi Ushul al-Fiqh, (Beirut: Dar al-Kutub alIlmiyah, 1985).

Jalaluddin ar-Rahmat as-Suyuthi, al-Asybah wa an-Nazair, (Singapura: Sulaiman Mar'I, tt.). 
Muhammad Abu Zahrah, Ushul al-Fiqh, (Mesir: Dar al-Fikr alArabi, 1958).

Muhammad Ali as-Sais, Nasy'ah al-Fiqh al-Ijtihadi wa Athwarih, (Ttp: Mujma' al-Buhus al-Islamiyah, 1970).

Muhammad Fuad Abdul Baqi, al-Mu'jam al-Mufahras li Alfaz alQuran al-Karim, (Indonesia: Maktabah Dahlan, tt.).

Muhammad ibn Ali al-Bashri, al-Mu'tamad Fi Ushul alFiqh, (Damsyiq: Dar al-Fikr, 1965).

Muhammad Musa Towana, al-Ijtihad, (Mesir, Dar al-Kutub alHadisah, 1971).

Muhammad Salam Madkur, al-Ijtihad Fi Tasyri' al-Islami, (Kairo: Dar an-Nahdah al-Arabiyah, 1992).

Muhammad Ubaidillah al-As'adi, al-Mujiz Fi Ushul al-Fiqh, (Ttp: Dar as-Salam, 1990).

Sya'ban Muhammad Ismail, Ushûl al-Fiqh al-Muyassar, (Beirut: Dar Ibn Hazm, 2006).

al-Masyhur, Abdur Rahman bin Muhammad bin Husei. Bughyatu al-Mustarsyidin, (Tarem; Markaz al-Nur li alDirasat wa al-Abhats, $2009 \mathrm{M} / 1430 \mathrm{H})$.

Al-Syirazy, Al-Ma'ũnah fi al-Jadãl, (Kuwait: Jam'iyah al-Turaś al-Islamĩ, $1407 \mathrm{H})$.

Mushtada Sa'ide Al-Khin, Dirãsah tãrikhiyah lil fikhi wa ușũlihi, (Demasyqus: al-Syirkah al-Muttahidah li alTawzi', 1415 H/ 1995 M).

Musthafa Bashir al-Tharabalisy, Manhãju al-Bahśi wa alFatwã, (Yordania: Dar al-Fath, 2010 M/1431 H). 